\title{
Trends in Systemic Antibiotic Therapy of Endodontic Infections: a Survey among Dental Practitioners in Lithuania
}

\author{
Alexander Mende ${ }^{1}$, Tadas Venskutonis ${ }^{1}$, Migle Mackeviciute ${ }^{1}$ \\ ${ }^{1}$ Department of Dental and Oral Pathology, Medical Academy, Lithuanian University of Health Sciences, Kaunas, Lithuania.
}

\author{
Corresponding Author: \\ Alexander Mende \\ Department of Dental and Oral Pathology, Medical Academy \\ Lithuanian University of Health Sciences \\ Eiveniu 2, 50028 Kaunas \\ Lithuania \\ E-mail: amende.in@gmail.com
}

\begin{abstract}
Objectives: Prescription trends to certain antibiotic classes in Lithuania have been observed. Considering the potential contribution to antimicrobial resistance and the evidence of inappropriate prescriptions highlights, the periodical assessment of antibiotic consumption trends is required. The aim of this study was to assess prescription behaviours of Lithuanian general dental practitioners concerning the systemic antibiotic therapy of endodontic infections.

Material and Methods: A sample of 198 Lithuanian dentists, registered on the database of the Lithuanian Dental Chamber, provided anonymous information about their clinical work by means of an online questionnaire.

Results: Among the participants, antibiotics were prescribed in less than $20 \%$ of endodontic cases. Most common diagnosis for the prescription was symptomatic apical periodontitis with periostitis $(90 \%)$ and apical abscesses with systemic involvement (54\%). Amoxicillin and co-amoxiclav were the preferred choices for the antimicrobial therapy. The preference of clavulanic acid combination over simple usage of amoxicillin is increasing relative to the participants age $(\mathrm{P}=0.016)$ and working experience $(\mathrm{P}=0.008)$. Clindamycin is prescribed in cases of allergy to beta-lactams. Practitioners with less years of clinical activity were more likely to prescribe antibiotics for spreading infections, than their associates with more than 10 years of practice $(\mathrm{P}<0.001)$.

Conclusions: Clinicians of higher age were found to be more likely to prescribe broad-spectrum antibiotic combinations compared to their younger associates. The majority of practitioners were aware of the clinical recommendations.
\end{abstract}

Keywords: anti-bacterial agents; endodontics; periapical periodontitis; surveys and questionnaires.

Accepted for publication: 20 February 2020

To cite this article:

Mende A, Venskutonis T, Mackeviciute M.

Trends in Systemic Antibiotic Therapy of Endodontic Infections: a Survey among Dental Practitioners in Lithuania

J Oral Maxillofac Res 2020;11(1):e2

URL: http://www.ejomr.org/JOMR/archives/2020/1/e2/v11n1e2.pdf

doi: $10.5037 /$ jomr.2020.11102 


\section{INTRODUCTION}

The emerging problem of antibiotic resistance is an international concern that affects global medical progress and poses a continuous challenge for physicians worldwide [1, $]$ ]. Beside the problem of resistance, the antibiotic therapy poses risks of serious complications, involving drug-related adverse effects and allergic reactions $[\underline{3}, 4]$. Despite persistent efforts of control, antibiotic misuse and increasing counts of prescriptions are primarily responsible for the negative development. In Europe 7 - 9\% of all dispensed antibiotics in the primary care are prescribed by general dental practitioners (GDPs) [5]. Lithuania demonstrates an overall decline in numbers of antibiotic usage in the primary care sector. Nonetheless, prescription trends to certain antibiotic classes can be observed [6]. Antibiotic therapy regularly involves the utilization of systemic broad-spectrum agents, against recommendations of guidelines and on basis of clinical symptoms that do not justify their usage. In spite of their limited therapeutic value, the inadequate prescribing practices of systemic antibiotics in endodontic therapy have been thoroughly described in present studies and the available literature [5,7]. In order to design effective interventions to optimize antimicrobial prescribing in the dental practice, analysis of causes for the inappropriate usage is needed and influencing factors have to be understood [5]. In the light of recommendations, presented in the position statement of the European Society of Endodontics [3], the aim of this study was to provide a study on the prescription behaviour of Lithuanian general dental practitioners, concerning the systemic antibiotic therapy of endodontic infections.

\section{MATERIAL AND METHODS}

The study was conducted in the period of one month, from January until February 2019. For the collection of data, a questionnaire was mailed to 1269 Lithuanian dental practitioners, registered at the Lithuanian Dental Chamber, which gave their consent to the processing of personal data according to the EU General Data Protection Regulation, of which 213 accepted the invitation to participate. The questionnaire was carried out anonymously without identification of participants. Confidentiality and protection of research data was assured at all times. All participants have read the accompanying paper and given their consent to the surveying process. Ethical approval of the study was granted by the Bioethics Centre of the Lithuanian University of Health Science, Kaunas in December 2018 (approval no. BEC-OF-52). Together with a short summary and purpose of the study, the questionnaire consisted out of 10 singlechoice and 4 multiple-choice questions divided into an introductory part, concerning general information of participants and a clinical part with focus on methods of antibiotic usage in endodontic therapy. Clinicians have been asked to indicate diagnostic findings and forms of pathology, validating the systemic antibiotic aid according to their own clinical work. One question included a clinical case, in which the participants have been asked to list steps of treatment according to their individual assessment. Furthermore, participants had to indicate favoured first- and second choice antimicrobial agents as well as antibiotics chosen for patients with a history of allergies to beta-lactams. The clinical part of the survey was prepared on basis of criteria, presented in the guidelines of the European Society of Endodontology [3]. From the 213 enrolled dentists that accepted the invitation to participate in the study, a total of 198 practitioners licensed as GDP (excluding dental specialists) were included in the statistical analysis. Considering the geographic distribution of the respondents, both dentists from rural and urban areas of Lithuania are represented within the sample. For improved comparison and association of variables during the statistical analysis, the sample has been sorted into smaller groups, concerning their age, working experience and type of dental practice. Demographics of the sample are presented in Table 1. A summary of the surveying process and study population is illustrated in Figure 1.

Table 1. Demographics of the sample $(n=198)$

\begin{tabular}{l|c}
\hline \multicolumn{1}{c}{ Characteristic } & $\begin{array}{c}\text { Frequency } \\
\text { number (\%) }\end{array}$ \\
\hline Practitioner gender & $33(16.7)$ \\
\hline Male & $165(83.3)$ \\
\hline Female & $64(32.3)$ \\
\hline Practitioner age & $49(24.7)$ \\
\hline$<29$ & $28(14.1)$ \\
\hline $30-39$ & $57(28.8)$ \\
\hline $40-49$ & $67(33.8)$ \\
\hline$>50$ & $33(16.7)$ \\
\hline Years of clinical activity & $22(11.1)$ \\
\hline $1-5$ & $76(38.4)$ \\
\hline $6-10$ & $126(63.6)$ \\
\hline $11-20$ & $30(15.2)$ \\
\hline$>20$ & $42(21.2)$ \\
\hline Type of dental practice & $141(78.3)$ \\
\hline Private practice & $39(27.9)$ \\
\hline Community dental service & $18(9.1)$ \\
\hline Both, private and community service
\end{tabular}




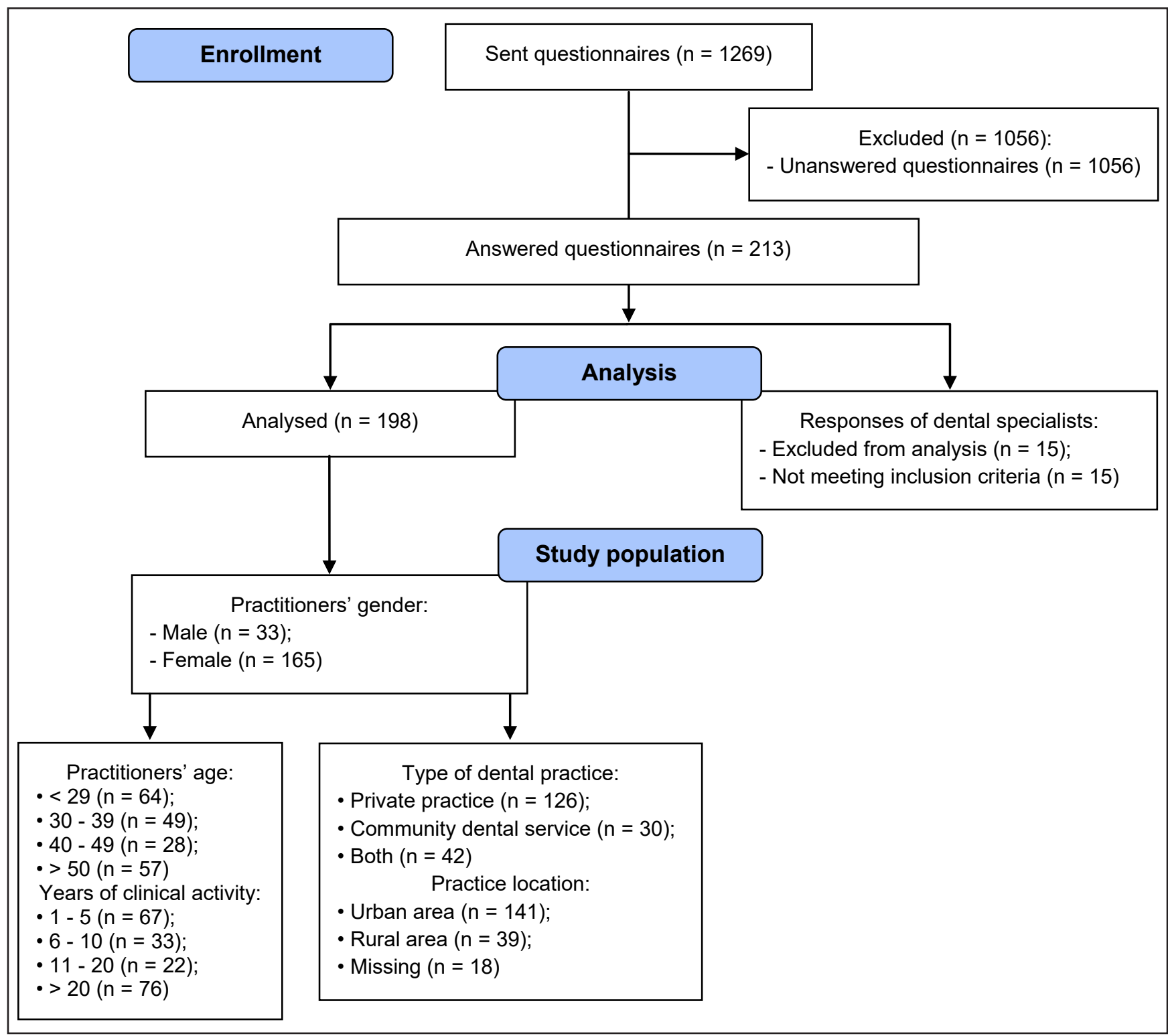

Figure 1. CONSORT 2010 Flow Diagram.

\section{Statistical analysis}

In the statistical analysis, relationships between two categorical variables were tested using Pearson's Chisquared test of independence. The relation between variables was significant when $\mathrm{P}<0.05$. When Chisquare assumptions were not met, Fisher's exact test was performed. The sample size was determined using priori probability. A sample size of 198 participants thereby allows to detect medium effect size of $h=0.4$ at 0.8 power and $\alpha=0.05$.

\section{RESULTS}

The majority of clinicians in this sample were found to prescribe systemic antibiotics in less than $20 \%$ of treated endodontic cases. Concerning this, practitioners working in the community dental service tend to utilize antibiotic agents more frequently than their colleagues in the private sector. The ratio of chosen antibiotic agents is demonstrated in Figure 2.

For the initial antibiotic therapy, questioning of all participants has shown, that amoxicillin was chosen in $79 \%$ of cases, followed by co-amoxiclav $(17 \%)$. Just $3 \%$ of all, in the study included, dentists preferred the initial treatment with penicillin $\mathrm{V}$ to other antimicrobial agents. Considering the second-choice prescribed antibiotic, co-amoxiclav has been found to be the favoured choice in $54 \%$ of cases. Exclusively $16 \%$ stated to prescribe clindamycin. Statistical analysis of association revealed, that the preference of clavulanic acid combination over simple usage of amoxicillin is increasing relative to the participants age $(\mathrm{P}=0.016)$ and working experience $(\mathrm{P}=0.008)$ (Table 2). 


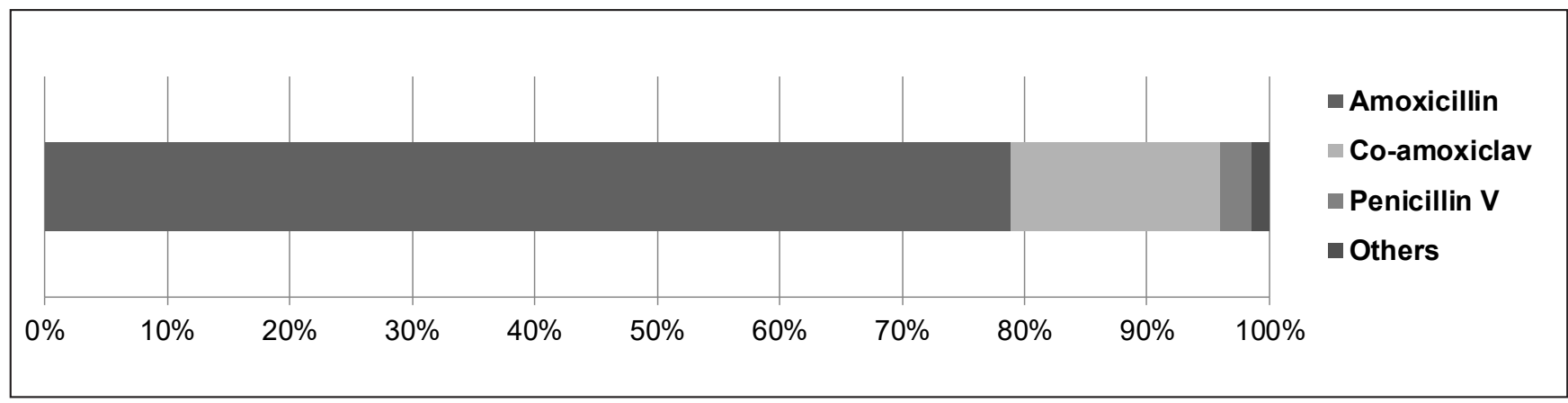

Figure 2. Ratio of prescribed first-line antibiotics by Lithuanian general dental practitioners.

In the matter of antibiotic usage for patients with allergy to beta lactams, every second GDP (54\%) stated clindamycin as therapeutic agent of choice. $31 \%$ of respondents indicated macrolides and $15 \%$ prescribed cephalosporins for this group of patients. Concerning endodontic pathologies and identification of clinical findings (Table 3), 90\% of dentists stated the diagnosis of symptomatic apical periodontitis with spreading infection to the periosteum and 17\% symptomatic apical periodontitis without further progression as indication criteria for the usage of systemic antibiotics. Prescriptions for symptomatic pulpitis were reported by less than $1 \%$ of all participants. $60 \%$ identified the usage for localized acute apical abscesses, however $8 \%$ for abscesses without systemic involvement.

Therapeutic assessment of an abscess with discrete localized swelling in absence of symptoms of spreading infection has shown that $48 \%$ of all practitioners would consider broad-spectrum antibiotics for the given pathology. 52\% have been found to perform incision and drainage of the abscess without further measures. Alone $5 \%$ stated to take samples for microbiologic analysis. In regards of clinical experience, the association of nominal values estimated that practitioners with less years of clinical activity were more likely to prescribe antibiotics for spreading infections, than their associates with more than 10 years of practice $(\mathrm{P}<0.001)$. Regarding the diagnosis of clinical findings, osteomyelitis, signs of systemic infection and the presence of inflammatory exudate after initial root canal therapy, were among the list of symptoms validating the prescription. Only $6 \%$ stated pain to percussion and biting, signs often associated with acute apical periodontitis. In terms of patient groups of special prophylactic need, immunological compromised patients diagnosed with apical abscess (79\%), patients with history of infective endocarditis (87\%), rheumatic heart diseases $(54 \%)$ and orthopaedic implants (25\%), were among the selected sub-groups in demand of antibiotic prophylaxis during the endodontic treatment.
Table 2. Frequency of amoxicillin (AMX) and amoxicillin clavulanate $(\mathrm{AMC})$ prescriptions relative to participants age $(\mathrm{P}=0.016)$ and years of clinical activity $(\mathrm{P}=0.008)$

\begin{tabular}{|c|c|c|c|c|c|}
\hline \multirow{2}{*}{$\begin{array}{l}\text { Study population } \\
\qquad(\mathrm{n}=198)\end{array}$} & \multicolumn{2}{|c|}{ Amoxicillin } & \multicolumn{2}{|c|}{$\begin{array}{l}\text { Amoxicillin } \\
\text { clavulanate }\end{array}$} & \multirow[t]{2}{*}{ P value ${ }^{\mathrm{a}}$} \\
\hline & $\mathbf{N}$ & $\%$ & $\mathbf{N}$ & $\%$ & \\
\hline \multicolumn{6}{|l|}{ Participants age } \\
\hline Below 40 years & 95 & 88 & 13 & 12 & \multirow{2}{*}{0.016} \\
\hline Above 40 years & 61 & 74.4 & 21 & 25.6 & \\
\hline \multicolumn{6}{|c|}{ Time of clinical activity } \\
\hline $1-10$ years & 85 & 89.5 & 10 & 10.5 & \multirow{2}{*}{0.008} \\
\hline More than 10 years & 71 & 74.7 & 24 & 25.3 & \\
\hline
\end{tabular}

aStatistically significant at $\mathrm{P}<0.05$ (Fischer's exact test). $\mathrm{N}=$ number $($ total $\mathrm{AMX}=156 ; \mathrm{AMC}=34)$.

Table 3. Most common diagnoses and clinical findings for systemic antibiotic usage in endodontic therapy as reported by Lithuanian general dental practitioners

\begin{tabular}{l|c}
\hline & $\begin{array}{c}\text { Frequency } \\
\text { (\%) }\end{array}$ \\
\hline \multicolumn{2}{l}{ Diagnosis } \\
\hline Symptomatic apical periodontitis with periostitits & 90.4 \\
\hline Cellulitis, spreading infection & 55.1 \\
\hline Acute apical abscess with sign of systemic infection & 54 \\
\hline Symptomatic apical periodontitis & 16.7 \\
\hline Acute apical abscess without systemic involvement & 8.1 \\
\hline Symptomatic pulpitis & 0.5 \\
\hline Clinical finding & 90.9 \\
\hline Osteomyelitis & 88.9 \\
\hline Elevated body temperature & 56.6 \\
\hline Localized fluctuant swelling & 51.5 \\
\hline Lymphadenopathy & 46 \\
\hline Repeated exudation after root canal treatment & 6.5 \\
\hline $\begin{array}{l}\text { Localized fluctuant swelling (in absence of systemic } \\
\text { infection) }\end{array}$ & 5.6 \\
\hline Pain to percussion and biting & 3 \\
\hline Non vital teeth & 2 \\
\hline Periapical radiolucency & 1 \\
\hline Widening of periodontal space & \\
\hline &
\end{tabular}




\section{DISCUSSION}

Putting the obtained results of this sample in relation with other European countries shows, that the mean of antimicrobial prescription numbers was relatively lower than those found in the UK or Turkey $[\underline{5}, \underline{8}, \underline{9}]$. Yet received data of prescription criteria gives reason to assume, that recommended indications are not implemented by all participants. Clinical trials provide evidence, that antibiotics do not relief pain or swelling in the therapy of apical pathologies without systemic involvement. In fact, due to the restricted blood flow within infected root canals, systemic antibiotics cannot effectively reach the therapeutic area to erase microorganisms [10-12]. Acute apical abscesses and localized fluctuant swellings are preferably managed mechanically by means of root canal treatment or drainage after incision or tooth extraction. The adjunctive aid of antibiotics in addition to local procedures is only recommended in specific cases, to stop infections from spreading via interstitial and tissue spaces and must be monitored carefully, as antimicrobial agents may be ineffective or insufficient for the treatment $[\underline{3}, 10,13]$. However, when asked to provide therapy steps for the treatment of an abscess without indication of systemic infection, every second practitioner of the sample referred to empiric broad-spectrum antibiotics. Despite $17 \%$ of all surveyed GDPs have been found to utilize systemic antimicrobials for symptomatic apical periodontitis, obtained numbers were lower than those from previous years [14]. Contraindication of antibiotics for cases of symptomatic pulpitis was recognized throughout the sample, as it was stated by less than $1 \%$ of the respondents. In countries such as Spain and Croatia, the diagnosis of pulpitis still accounts for $22 \%$ and $7 \%$ of all cases in which antibiotics are prescribed $[15,16]$. In the therapy of immunosuppressed or medically compromised patients, antibiotic prophylaxis may be considered in the attempt to prevent postoperative infections [17]. Concerning antibiotic prophylaxis in terms of infective endocarditis, the European Society of Cardiology presents the opinion, that the routinely antibiotic prophylaxis is no longer indicated and includes only individual cases of high-risk patients [18].

As compared with the data of previous studies, the number of amoxicillin prescriptions has increased. A decline in the use of narrow-spectrum penicillins was observed [14]. Association between antibiotic prescriptions and years of clinical activity has shown, that with increasing years of experience, clinicians were more likely to prescribe amoxicillin in combination with potassium clavulanate. Even though co-amoxiclav is a popular choice among European dentists, its usage should be prioritized for high-risk patients or as second choice agent only, as the risks of emerging bacterial resistance and adverse effects predominate due to its broad antimicrobial spectrum $[3,4,10]$. On basis of the literature, both penicillin and amoxicillin have been found suitable for the first-line antibiotic therapy of endodontic pathologies $[10, \underline{13}, 19]$. A comparative study on treatment outcomes of dentoalveolar infections could find no differences in the therapy with penicillin, amoxicillin or co-amoxiclav [20]. Common susceptibility of endodontic microorganisms to penicillin makes it a relevant option for the first-line therapy [19]. For patients with a history of allergies to beta-lactams, the usage of clindamycin is advised and cephalosporins are contraindicated due to the risk of potential crosssensitivity [18]. Apart from that, lincosamides like clindamycin should not be considered routinely, as reports of microbial resistance showed association with methicillin-resistant Staphylococcus aureus (MRSA) [21]. Because of its unclear effectiveness and potential induction of resistance, antibiotics of the family of fluoroquinoles and glycopeptides are not recommended [18]. Last of all it is important to mention, that beside the analysed clinical criteria, also psychological factors such as time pressure, workload, or patient's expectation can negatively affect the clinician's decision to prescribe antibiotics [9]. Due to limitations in sample size it is recommended to repeat future studies with bigger samples, as some observed correlations were low. Yet due to its demographic variety, the sample can portray a representative cross section of Lithuanian general dental practitioners.

\section{CONCLUSIONS}

Most antimicrobial agents were selected in accordance with the clinical recommendations. Prescription preferences from narrow-spectrum penicillin $\mathrm{V}$ to amoxicillin were observed. With increasing age and years of experience, dental practitioners were more likely to prescribe broad-spectrum antibiotic combinations, compared to their younger colleagues. Obtained averages of prescription numbers were not relatively higher than in other European countries. Yet in terms of prescription criteria and antibiotic composition, disparities in clinician's expertise were seen. Within the limitations of this study, it is suggested that further programs of postgraduate education address the antimicrobial therapy, to allude risks of inappropriate usage and improve the adaptation of available prescription guidelines. 


\section{ACKNOWLEDGMENTS AND DISCLOSURE study. STATEMENTS}

The authors report no conflict of interest related to this

The authors would like to acknowledge the Lithuanian Dental Chamber for its help in distributing the survey and thank all dental practitioners, which participated in the study.

\section{REFERENCES}

1. World Health Organization (WHO). Global action plan on antimicrobial resistance. Geneva, Switzerland: World Health Organization; 2015 May 25. A68/A/CONF./1 Rev.1. [URL: http://apps.who.int/gb/ebwha/pdf files/WHA68/A68 ACONF1Rev1-en.pdf]

2. Cassini A, Högberg LD, Plachouras D, Quattrocchi A, Hoxha A, Simonsen GS, Colomb-Cotinat M, Kretzschmar ME, Devleesschauwer B, Cecchini M, Ouakrim DA, Oliveira TC, Struelens MJ, Suetens C, Monnet DL; Burden of AMR Collaborative Group. Attributable deaths and disability-adjusted life-years caused by infections with antibiotic-resistant bacteria in the EU and the European Economic Area in 2015: a population-level modelling analysis. Lancet Infect Dis. 2019 Jan;19(1):56-66. [Medline: 30409683] [doi: 10.1016/S1473-3099(18)30605-4]

3. Segura-Egea JJ, Gould K, Şen BH, Jonasson P, Cotti E, Mazzoni A, Sunay H, Tjäderhane L, Dummer PMH. European Society of Endodontology position statement: the use of antibiotics in endodontics. Int Endod J. 2018 Jan;51(1):20-25. [Medline: 28436043] [doi: 10.1111/iej.12781]

4. Leffler DA, Lamont JT. Clostridium difficile infection. N Engl J Med. 2015 Apr 16;372(16):1539-48. [Medline: 25875259] [doi: 10.1056/NEJMra1403772]

5. Cope AL, Francis NA, Wood F, Chestnutt IG. Antibiotic prescribing in UK general dental practice: a cross-sectional study. Community Dent Oral Epidemiol. 2016 Apr;44(2):145-53. [Medline: 26507098] [doi: 10.1111/cdoe.12199]

6. European Centre for Disease Prevention and Control. Antimicrobial consumption database (ESAC-Net). Consumption of antibiotics for systemic use in the community. Stockholm: ECDC; 2019. [URL: http://ecdc.europa.eu/]

7. Foucault C, Brouqui P. How to fight antimicrobial resistance. FEMS Immunol Med Microbiol. 2007 Mar;49(2):173-83. [Medline: 17181560] [doi: 10.1111/j.1574-695X.2006.00172.x]

8. Kaptan RF, Haznedaroglu F, Basturk FB, Kayahan MB. Treatment approaches and antibiotic use for emergency dental treatment in Turkey. Ther Clin Risk Manag. 2013;9:443-9. [Medline: 24307834] [PMC free article: 3845533 ] [doi: 10.2147/TCRM.S52009]

9. Cope AL, Barnes E, Howells EP, Rockey AM, Karki AJ, Wilson MJ, Lewis MA, Cowpe JG. Antimicrobial prescribing by dentists in Wales, UK: findings of the first cycle of a clinical audit. Br Dent J. 2016 Jul 8;221(1):25-30. [Medline: 27388087] [doi: 10.1038/sj.bdj.2016.496]

10. Segura-Egea JJ, Gould K, Şen BH, Jonasson P, Cotti E, Mazzoni A, Sunay H, Tjäderhane L, Dummer PMH. Antibiotics in Endodontics: a review. Int Endod J. 2017 Dec;50(12):1169-1184. [Medline: 28005295] [doi: 10.1111/iej.12741]

11. Cope AL, Chestnutt IG. Inappropriate prescribing of antibiotics in primary dental care: reasons and resolutions. Prim Dent J. 2014 Nov;3(4):33-7. [Medline: 25668373] [doi: 10.1308/205016814813877333]

12. Keenan JV, Farman AG, Fedorowicz Z, Newton JT. A Cochrane systematic review finds no evidence to support the use of antibiotics for pain relief in irreversible pulpitis. J Endod. 2006 Feb;32(2):87-92. [Medline: 16427452] [doi: 10.1016/j.joen.2005.10.029]

13. Dar-Odeh NS, Abu-Hammad OA, Al-Omiri MK, Khraisat AS, Shehabi AA. Antibiotic prescribing practices by dentists: a review. Ther Clin Risk Manag. 2010 Jul 21;6:301-6. [Medline: 20668712] [PMC free article: 2909496] [doi: 10.2147/TCRM.S9736]

14. Skučaitė N, Pečiulienè V, Manelienė R, Mačiulskienè V. Antibiotic prescription for the treatment of endodontic pathology: a survey among Lithuanian dentists. Medicina (Kaunas). 2010;46(12):806-13. [Medline: 21532284] [doi: 10.3390/medicina46120113]

15. Perić M, Perković I, Romić M, Simeon P, Matijević J, Mehičić GP, Krmek SJ. The Pattern of Antibiotic Prescribing by Dental Practitioners in Zagreb, Croatia. Cent Eur J Public Health. 2015 Jun;23(2):107-13. [Medline: 26851419] [doi: 10.21101/cejph.a3981]

16. Alonso-Ezpeleta O, Martín-Jiménez M, Martín-Biedma B, López-López J, Forner-Navarro L, Martín-González J, Montero-Miralles P, Jiménez-Sánchez MDC, Velasco-Ortega E, Segura-Egea JJ. Use of antibiotics by spanish dentists receiving postgraduate training in endodontics. J Clin Exp Dent. 2018 Jul 1;10(7):e687-e695. [Medline: 30057712] [PMC free article: 6057074] [doi: 10.4317/jced.54894]

17. Daly CG. Antibiotic prophylaxis for dental procedures. Aust Prescr. 2017 Oct;40(5):184-188. [Medline: 29109602] [PMC free article: 5662431] [doi: 10.18773/austprescr.2017.054] 
18. Habib G, Lancellotti P, Antunes MJ, Bongiorni MG, Casalta JP, Del Zotti F, Dulgheru R, El Khoury G, Erba PA, Iung B, Miro JM, Mulder BJ, Plonska-Gosciniak E, Price S, Roos-Hesselink J, Snygg-Martin U, Thuny F, Tornos Mas P, Vilacosta I, Zamorano JL; ESC Scientific Document Group . 2015 ESC Guidelines for the management of infective endocarditis: The Task Force for the Management of Infective Endocarditis of the European Society of Cardiology (ESC). Endorsed by: European Association for Cardio-Thoracic Surgery (EACTS), the European Association of Nuclear Medicine (EANM). Eur Heart J. 2015 Nov 21;36(44):3075-3128. [Medline: 26320109] [doi: 10.1093/eurheartj/ehv319]

19. Skucaite N, Peciuliene V, Vitkauskiene A, Machiulskiene V. Susceptibility of endodontic pathogens to antibiotics in patients with symptomatic apical periodontitis. J Endod. 2010 Oct;36(10):1611-6. [Medline: 20850663] [doi: 10.1016/j.joen.2010.04.009]

20. Kuriyama T, Absi EG, Williams DW, Lewis MA. An outcome audit of the treatment of acute dentoalveolar infection: impact of penicillin resistance. Br Dent J. 2005 Jun 25;198(12):759-63; discussion 754; quiz 778. [Medline: 15980845] [doi: 10.1038/sj.bdj.4812415]

21. Pipalova R, Vlcek J, Slezak R. The trends in antibiotic use by general dental practitioners in the Czech Republic (2006-2012). Int Dent J. 2014 Jun;64(3):138-43. [Medline: 24410046] [doi: 10.1111/idj.12089]

\section{To cite this article:}

Mende A, Venskutonis T, Mackeviciute M.

Trends in Systemic Antibiotic Therapy of Endodontic Infections: a Survey among Dental Practitioners in Lithuania

J Oral Maxillofac Res 2020;11(1):e2

URL: http://www.ejomr.org/JOMR/archives/2020/1/e2/v11n1e2.pdf

doi: $10.5037 /$ jomr.2020.11102

Copyright (C) Mende A, Venskutonis T, Mackeviciute M. Published in the JOURNAL OF ORAL \& MAXILLOFACIAL RESEARCH (http://www.ejomr.org), 31 March 2020.

This is an open-access article, first published in the JOURNAL OF ORAL \& MAXILLOFACIAL RESEARCH, distributed under the terms of the Creative Commons Attribution-Noncommercial-No Derivative Works 3.0 Unported License, which permits unrestricted non-commercial use, distribution, and reproduction in any medium, provided the original work and is properly cited. The copyright, license information and link to the original publication on (http://www.ejomr.org) must be included. 